\title{
Ethical Aspects of the Glasgow Effect
}

\author{
David M. Shaw
}

Received: 8 September 2014 / Accepted: 14 January 2015 /Published online: 21 February 2015

(C) Journal of Bioethical Inquiry Pty Ltd. 2015

\section{Introduction}

This editorial introduces this special issue of the Journal of Bioethical Inquiry on global health by presenting an analysis of the ethical implications of the Glasgow effect, the curious phenomenon whereby inhabitants of Scotland's largest city have substantially higher mortality rates than their counterparts in similar British cities, despite adjustment for factors such as socioeconomic status, obesity, smoking, drinking, and drug use. The Glasgow effect represents a health inequality that cannot currently be addressed, as its causes are as yet unidentified. As such, it raises several ethical issues. Parents may even have an ethical obligation to move their children away from Glasgow to prevent them being affected by the effect.

The Glasgow effect is perhaps the most perplexing health inequality. It represents unfairness with an unknown cause and is composed of several different elements. The most basic fact is that socioeconomically disadvantaged people (SDP) are worse off in terms of health than socioeconomically advantaged people (SAP) in Glasgow. This is a typical pattern of health inequality, and most cities in the developed world exhibit it. However, the first curious fact is that the disparity between SDP and SAP in Glasgow is more pronounced than almost anywhere else, with differences

D. M. Shaw $(\bowtie)$

Institute for Biomedical Ethics, University of Basel,

Bernoullistrasse 28, CH-4056 Basel, Switzerland

e-mail: david.shaw@unibas.ch in life expectancy of up to 30 years. Second, SDP in Glasgow have substantially worse health outcomes than SDP elsewhere, even after adjustment for variables such as consumption of alcohol, obesity, and smoking. And third, SAP in Glasgow, despite their health advantages over SDP in Glasgow, are 30 percent more likely to die young than SAP elsewhere: "premature deaths are more than 30\% higher [than in Liverpool and Manchester], and all deaths around 15\% higher" (Walsh et al. 2010a, 32; Walsh et al. 2010b; McCartney et al. 2011). Despite at least 17 different hypotheses (see Table 1), the cause of these effects is unknown. In a sense, there are at least three Glasgow effects, and some confusion has arisen because people use the phrase to refer to different things at different times. This paper addresses some ethical issues related to the second and third Glasgow effects listed above.

\section{The Ethical Conundrum of the Glasgow Effect}

It is now widely recognised that health inequalities are frequently unfair and measures should be taken to reduce them. Indeed, the two stated aims of the Scottish Government with regard to health are to improve health and fight health inequalities (NHS Health Scotland 2014). There are many ways in which health inequalities can be reduced. People can be encouraged via advertising and health education to live healthier lives, which will improve their health and also can lessen inequalities if campaigns are aimed at those experiencing inequalities. Most people are aware that it is unhealthy to 
Table 1 Hypotheses regarding the cause of the Glasgow effect (adapted from Walsh et al. 2010a)

\begin{tabular}{|c|c|}
\hline Explanation type & Hypothesis \\
\hline Artefactual & $\begin{array}{l}\text { Deprivation } \\
\text { Migration }\end{array}$ \\
\hline Downstream & $\begin{array}{l}\text { Health behaviours } \\
\text { Individual values }\end{array}$ \\
\hline Midstream & $\begin{array}{l}\text { Culture of substance misuse } \\
\text { Boundlessness and alienation } \\
\text { Family, gender relations, and parenting } \\
\text { differences } \\
\text { Lower "social capital" } \\
\text { Sectarianism } \\
\text { Culture of limited social mobility } \\
\text { Health service supply or demand } \\
\text { Deprivation concentration }\end{array}$ \\
\hline Upstream & $\begin{array}{l}\text { Inequalities } \\
\text { Deindustrialisation } \\
\text { "Political attack" } \\
\text { Climatic differences } \\
\text { Genetic }\end{array}$ \\
\hline
\end{tabular}

smoke, to be obese or sedentary, and/or to drink to excess or use drugs. More fundamentally, many inequalities are the result of socioeconomic factors; improvements in job opportunities, basic education, and housing are recognised as important factors in reducing health inequalities in socioeconomically disadvantaged communities. Most people are also aware that poor education, unemployment, and unhealthy housing are bad for them, and they therefore can try to avoid these factors. The problem is that the causes of the Glasgow effect are unknown.

Here is an example to illustrate the problem: Gavin and Esther are a young couple raising two infants in a socioeconomically disadvantaged area. They try to buy healthy food for their children, they do not smoke, they exercise regularly, and they drink in moderation. As such, they live relatively healthy lifestyles and are doing the best they can for their children. However, the city they live in is different from other cities. In most regards it is like many other cities in the same country. It is a nice place to live, with a mix of poor, rich, and comfortablyoff people. But this city has a curious feature: people who live there are much more likely to die than people elsewhere, and no one knows why. While Gavin and Esther love their home city, they don't want to become victims of this strange, unexplained effect. More to the point, they don't want their children to become its victims, either. But what can they do to avoid this effect, when even experts don't know what causes it? Gavin, Esther, and their children are victims of the Glasgow effect. No matter how healthy their lifestyles, they are at increased risk of premature mortality. This is strikingly unfair. Generally, people can take measures to increase their chances of avoiding future disease by living healthy lives. The Glasgow effect is different: we don't know what causes it, so we can't stop it happening, which is unjust. It represents a third type of health inequality: one that seems impossible to avoid.

\section{Avoiding the Glasgow Effect}

Actually, there is one way to avoid the Glasgow effect: leave Glasgow (or West Central Scotland, as the effect is actually more widespread). This might seem like a drastic measure, but it is the only one available. The only known cause of the Glasgow effect is geography, and the only way of avoiding a geographical effect is to move to a different area. The suggestion that people should move away from their hometown in order to increase their lifespan has a hint of the surreal about it, but a potential increase of 10 years in life expectancy is no trifling matter; the mystery of the Glasgow effect might be solved in a few years, but it might not. Do you stay where you are and run the risk of dying several years younger or move away and avoid this risk? Just as we do not know the cause of the Glasgow effect, we do not know exactly who it will affect, but a rational deliberator might well conclude that there is no point in running the risk. Despite the obvious answer to this Glaswegian wager, it is likely that status quo bias (Bostrom and Ord 2006) would cause many people living in Glasgow to remain, as many people would be reluctant to leave behind their roots and communities despite any prospective benefit.

However, we can imagine a hypothetical scenario posing similar levels of risk that would probably lead to a more urgent reaction. If a weak "dirty bomb" was detonated in Glasgow and the consequent increase in background radiation increased the risk of early mortality by more than 15 percent (the same as the Glasgow effect), it is likely that many people would leave the city fairly quickly despite any status quo bias, even if measures could be taken to reduce the exposure to radiation of those who stayed in Glasgow. This example illustrates that it is not unreasonable to avoid a potential 
negative health effect by moving away from a particular city. It also highlights that people may take a health threat tied to a specific event more seriously than one that has ambiguous varied causes, such as the Glasgow effect.

Another important point is that, while adults can freely decide whether to live with the added risk of residing in Glasgow, children cannot. As such, it could be argued that parents who wish to maximise their children's potential welfare should move away from the locus of the effect if at all possible; doing so could add 10 years to their children's lives. Research suggests that Glaswegian children constitute the only group not affected by the Glasgow effect; they are no less healthy than their counterparts elsewhere (McCartney et al. 2011; Walsh et al. 2010a). Therefore, moving away quickly might avoid the Glasgow effect entirely, particularly if the Glasgow effect is partially caused by childhood experiences (Donnelly 2010; it is not yet known whether moving away from Glasgow as an adult helps avoid the effect). Interestingly, it may already be too late for Gavin and Esther to prevent the effect from affecting their children; a recent study suggests that healthharming DNA demethylation may affect the genes that adults pass on to children, meaning that the Glasgow effect may disadvantage children before they are even conceived (McGuinness et al. 2012). However, this does not mean that any attempt to avoid the Glasgow effect is doomed; rather, it means that those who wish to protect their children and grandchildren from the effect should take action as soon as possible.

While moving away from Glasgow might increase children's long-term health chances, doing so raises some ethical problems of its own. First, there is the objection that moving elsewhere is akin to deserting a sinking ship and shows a distinct lack of solidarity. Both of these criticisms are true to some extent, but given the choice between solidarity and living longer, many would choose the latter. Second, while moving away might decrease the risk of early death, doing so also will disadvantage both adults and children by removing them from their support networks of family and friends, which could itself worsen well-being. This objection has more force than the first, and it is possible that any benefits conferred by avoiding the effect might be outweighed by the disutility of living far from one's (and one's children's) family and friends. Third, if migration from Glasgow improves the health of those who leave, this would ultimately result in an increase in the
Glasgow effect; those left behind in Glasgow would experience increased inequality in contrast to those living elsewhere precisely because people left to avoid the effect. This objection is more theoretical and has little practical force. Finally, those most able to move away are more likely to be better off, meaning that the worse off in Glasgow are also disadvantaged in terms of being less able to avoid the Glasgow effect. This is true, but can hardly be used as an argument against moving away for those who can do so. All four of these objections are valid, but none of them appears particularly forceful when weighed against the fact that moving away might mean living several years longer.

\section{Conclusion}

The Glasgow effect raises several ethical issues. If the aim of the Scottish Government is to reduce health inequalities, then identifying the causes of this unfair health effect should be a top priority. The only option currently available to people who want to maximise their own health and particularly that of their children is to leave Glasgow (or indeed Scotland, as there is also a Scotland effect in comparison with the rest of the United Kingdom). This might seem like a drastic option, and it does raise several ethical issues of its own. Nonetheless, it is an undeniable fact that people who live outside of Glasgow enjoy substantially lower rates of premature mortality, even if we do not know why. Status quo bias will probably lead most people to continue living in Glasgow, despite the increased risk to their health and that of future generations.

\section{References}

Bostrom, N., and T. Ord. 2006. The reversal test: Eliminating status quo bias in applied ethics. Ethics 116(4): 656-679.

Donnelly, P.D. 2010. Explaining the Glasgow effect: Could adverse childhood experiences play a role? Public Health 124(9): 498-499.

McCartney, G., C. Collins, D. Walsh, and D. Batty. 2011. Accounting for Scotland's excess mortality: Towards a synthesis. Glasgow: Glasgow Centre for Population Health. http://www.gcph.co.uk/assets/0000/1080/GLA147851_ Hypothesis_Report_2_pdf. Accessed December 18, 2012.

McGuinness, D., L.M. McĞlynn, P.C.D. Johnson, et al. 2012. Socio-economic status is associated with epigenetic differences in the pSoBid cohort. International Journal of Epidemiology 41(1): 151-160. doi:10.1093/ije/dyr215. 
NHS Health Scotland. 2014. Equalities and health inequalities. http://www.healthscotland.com/equalities/healthinequalities/index.aspx. Accessed December 18, 2012.

Walsh, D., N. Bendel, R. Jones, and P. Hanlon. 2010a. Investigating a "Glasgow effect": Why do equally deprived UK cities experience different health outcomes? Glasgow:
Glasgow Centre for Population Health. http://www.gcph.co. uk/assets/0000/0087/Investigating_a_Glasgow_Effect_for_ web.pdf. Accessed December 18, 2012.

Walsh, D., N. Bendel, R. Jones, and P. Hanlon. 2010b. It's not “just deprivation": Why do equally deprived UK cities experience different health outcomes? Public Health 124(9): 487-495. 